Vol.05, No.01, April 2019

Doi: 10.24198/cosmogov.v2i2.xxxxx

\title{
AKUNTABILITAS PENGELOLAAN DANA DESA DALAM PEMBANGUNAN INFRASTRUKTUR DI DESA TEGALREJO KECAMATAN GEDANGSARI KABUPATEN GUNUNGKIDUL TAHUN 2016
}

\author{
Muhammad Dwi Nurfaisal ${ }^{1}$ \\ Dyah Mutiarin ${ }^{2}$ \\ Sakir $^{3}$ \\ ${ }^{I}$ Magister Ilmu Pemerintahan, Universitas Muhammadiyah Yogyakarta \\ ${ }^{2}$ Program Studi Ilmu Pemerintahan, FISIP, Universitas Muhammadiyah Yogyakarta \\ ${ }^{3}$ Program Studi Ilmu Pemerintahan, FISIP, Universitas Muhammadiyah Yogyakarta \\ Email: faisaldwinn3@gmail.com
}

\begin{abstract}
ABSTRAK
Dana Desa merupakan hak yang dimiliki oleh desa. Undang-undang Nomor 6 Tahun 2014 tentang Desa menjelaskan bahwa keuangan desa harus dikelola dengan memperhatikan azaz-azas akuntabel, transparan, partisipatif, serta dilaksanakan dengan tertib dan disiplin anggaran. Berazazkan pada akuntabilitas, pemerintah desa memiliki kewajiban untuk mengelola Dana Desa dan mempertanggungjawabkannya. Dana Desa salah satunya diperuntukkan dalam pembangunan infrastruktur yang dapat memberikan manfaat bagi kesejahteraan masyarakat pedesaan. Penelitian ini bertujuan menganalisis akuntabilitas pengelolaan dana desa untuk pembangunan infrastruktur desa. Penelitian ini menggunakan metode kualitati dengan teknik pengumpulan data melalui wawancara dan dokumentasi yang bersumber dari pemerintah desa, masyarakat, dan BPD. Temuan dalam penelitian ini adalah bahwa akuntabilitas pengelolaan dana desa untuk pembangunan infrastruktur Desa Tegalrejo kurang baik. Hal tersebut disebabkan oleh berberapa masalah yang tediri dari: Belum ada rincian waktu terkait waktu pelaksanaan; Kurang transparan dalam menyampaikan laporan pengelolaan anggaran; Belum semuanya masyarakat berpartisipasi aktif dalam pelaksanaan pembangunan infrastruktur; Belum maksimal dalam pemanfaatan Sistem Informasi Desa (SID) sebagai sarana untuk menginformasikan laporan pengelolaan Dana Desa; Perangkat desa yang kurang berkoordinasi dengan masyarakat terkait pelaksanaan pembangunan infrastruktur.
\end{abstract}

Kata kunci: akuntabilitas; pengelolaan dana desa; pembangunan infrastruktur

\section{ABSTRACT}

The Village Fund is a right owned by the village. Law No. 6 of 2014 on Villages explains that village finances should be managed with due regard to accountable, transparent, participatory, and implemented principles with discipline and budgetary discipline. Based on accountability, the village government has an 
Vol.05, No.01, April 2019

Doi: $10.24198 / \operatorname{cosmogov.v2i2.xxxxx}$

obligation to manage the Village Fund and to account for it. The Village Fund is one of them devoted to the development of infrastructure whose output can benefit the welfare of rural communities. This study aims to analyze the accountability of village fund management for infrastructure development located in Tegalrejo Village, Gedangsari District, Gunungkidul Regency. This study uses a qualitative method. Data collection techniques used are interviews and documentation sourced from village government, community, and BPD. The finding in this research is that accountability of village fund management for Tegalrejo Village infrastructure development is poor. This is caused by several problems that consist of: no details of time related to the time of implementation program; less transparent in delivering budget management reports; not all communities have been actively participating in the implementation; has not been maximized in the utilization of Village Information System (SID) in the form of website as a means to inform Village Fund management report; and village apparatus that lack coordination with the community related to the implementation of infrastructure development.

Keywords: accountability; village fund management; infrastructure development

\section{PENDAHULUAN}

Kemandirian desa merupakan keharusan yang dimiliki desa sejak disahkannya Undang-Undang Nomor 6 Tahun 2014 tentang Desa. UU Desa tersebut memberikan kewenangan kepada desa agar dapat memiliki kemandirian sehingga dapat memiliki daya saing yang baik. Salah satu kemandirin desa merupakan bentuk penyelenggaraan pembangunan yang dilaksanakan oleh pemerintah desa. Tujuannya adalah sebagai cara meningkatkan kesejahteraan dan kualitas hidup yang lebih baik serta sebagai penanggulangan kemiskinan masyarakat pedesaan. Untuk mewujudkan tujuan pembangunan desa tersebut, maka setiap desa mendapatkan Dana Desa.

Dana Desa merupakan dana yang berasal dari APBN yang disebut dengan Rekening Kas Umum Negara
(RKUN) sebagai tempat penyimpanan uang negara dan telah di tetapkan oleh menteri keuangan selaku bendahara negara. Kemudian di transfer ke daerah melalui Rekening Kas Umum Daerah (RKUD) yaitu tempat penyimpanan uang daerah yang telah ditetapkan oleh bupati/walikota untuk menampung seluruh penerimaan daerah dan membayar seluruh pengeluaran daerah. Selanjutnya desa menerima transfer dari daerah melalui Rekening Kas Desa (RK Desa) yang diperuntukkan sebagai tempat penyimpanan uang untuk penerimaan dana dari daerah dan membayar seluruh pengeluaran desa yang di catatat dalam APB Desa. Kemudian masing-masing pemerintah desa harus mempertanggungjawabkan penggunaan Dana Desa (akuntabel) 
Vol.05, No.01, April 2019

Doi: $10.24198 /$ cosmogov.v2i2.xxxxx

dan transparan dalam pengelolaan Dana Desa tersebut.

Katarina (dalam Fajar, 2016) menjelaskan pengelolaan keuangan publik harus berasaskan akuntabilitas, pemerintah selaku pengelola keuangan publik harus melakukan yang pertama yaitu, harus memiliki perundang-undangan yang menjamin pemerintah untuk mempublikasikan transparansi anggaran kepada masyarakat agar bisa diakses oleh masyarakat. Kedua, Pemerintah harus: (a) mempublikasikan rencana penggunaan anggaran kepada masyarakat, (b) melakukan pertemuan secara rutin bersama masyarakat sekurang-kurangnya setiap tiga bulan sekali, seperti Musyawarah Rencana Pembangunan (Musrenbang), (c) mempublikasikan hasil laporan keuangan, (d) memiliki kedekatan yang proaktif kepada masyarakat terkait publikasi transparansi anggaran melalui website, (e) mengalokasikan Sumber Daya Manusia (SDM) untuk mentransformasikan informasi kepada masyarakat, (f) profesional dalam melayani masyarakat, (g) dari semua point tersebut, harus tertera dalam undang-undang.

Berangkat dari tema besar yang dibahas, maka Desa Tegalrejo merupakan obyek yang tepat untuk menggali informasi akuntabilitas pemerintah desa dalam mengelola Dana Desa khusus yang diperuntukkan dalam pembangunan infrastruktur. Desa Tegalrejo merupakan penerima Dana Desa terbesar yang berada di Kecamatan Gedangsari Kabupaten Gunungkidul serta mendapatkan amanat untuk mengelola Dana Desa tersebut dengan memprioritaskan pembangunan. Total dana yang diterima Desa Tegalrejo untuk pembangunan yaitu sebesar $\mathrm{Rp}$ 818.533.600 dan salah satu penggunaannya untuk pembangunan insfrastruktur. Jumlah dana tersebut sesuai dengan yang telah di rencanakan dalam Rencana Kerja Desa (RKP Desa) Tegalrejo dalam prioritas pembangunan pada tahun 2016. Pembangunan yang dilaksanakan Pemerintah Desa Tegalrejo juga harus memenuhi asas Akuntabel, sebagaimana yang diamanatkan dalam Permendagri No. 113 Tahun 2014 Pasal 2 ayat 1. Akuntabilitas Pemerintah Desa Tegalrejo dalam pelaksanaan pembangunan infrastruktur di tahun 2016 harus diikuti dengan transparansi anggaran yang nantinya masyarakat Desa Tegalrejo mengetahui apa yang menjadi prioritas pembangunan yang dilaksanakan Pemerintah Desa Tegalrejo di tahun 2016. Oleh karena itu, penelitian ini menganalisis akuntabilitas pengelolaan Dana Desa untuk pembangunan infrastruktur di Desa Tegalrejo Tahun 2016.

\section{METODE PENELITIAN}

Penelitian menggunakan model metode deskriptif kualitatif. 
Vol.05, No.01, April 2019

Doi: $10.24198 /$ cosmogov.v2i2.xxxxx

Pengumpulan data yang digunakan yaitu dengan cara melakukan wawancara dengan pihak terkait atau pemilik data serta mengolah dokumen yang ditulis ulang menjadi paragraf. Moleong (2016:6) menjelaskan bahwa penelitian kualitatif adalah penelitian yang bermaksud memahami fenomena tentang apa yang dialami oleh subjek penelitian, misalnya perilaku, persepsi, motivasi, dan tindakan dengan cara deskripsi dalam bentuk kata-kata dan bahasa, pada suatu konteks khusus yang alamiah dengan memanfaatkan berbagai metode alamiah. Penelitian kualitatif dirasa sangat tepat untuk digunakan dalam penelitian yang akan dilakukan, karena penelitian ini sangat memberikan kesempatan yang luas kepada peneliti untuk memfokuskan ke dalam permasalahan yang akan diteliti secara mendalam. Teknik Pendekatan wawancara dan pengumpulan data terkait akuntabilitas pengelolaan Dana Desa dalam pembangunan infrastruktur di Desa Tegalrejo pada tahun 2016.

\section{HASIL DAN PEMBAHASAN}

Akuntabilitas pengelolaan

Dana Desa di Desa Tegalrejo memiliki beberapa klasifikasi dalam perencanaan hingga evaluasi. Mengukur akuntabilitas pengelolaan Dana Desa oleh Pemerintah Desa Tegalrejo, memiliki empat indikator yaitu sebagai berikut: 
Vol.05, No.01, April 2019

Doi: $10.24198 /$ cosmogov.v2i2.xxxxx

Undang-undang Nomor 6 Tahun 2014 tentang Desa menejelaskan bahwa dalam pengelolaan Dana Desa harus sesuai dengan peraturan yang berlaku. Perencanaan pengelolaan Dana Desa untuk pembangunan infrastruktur di Desa Tegalrejo harus memiliki kesesuaian antara RPJM Desa dengan RKP Desa. Seperti yang terjadi di lapangan (Desa Tegalrejo) ditemukan bahwa RPJM Desa Tegalrejo hanya diperuntukkan pada tahun 2014-2019, sedangkan di dalam Perbup Gunungkidul No.49 Tahun 2015 menyebutkan bahwa RPJM Desa harus memiliki perencanaan selama enam tahun atau selama satu periode pemerintahan desa. Melihat peraturan tersebut dapat ditemukan indikasi ketidaksesuaian antara penyusunan RPJM Desa dengan peraturan yang berlaku.

Menyikapi hal itu, Pemerintah Desa Tegalrejo memberikan klarifikasi bahwa pihaknya menyadari jika RPJM Desa Tegalrejo tidak sesuai dengan peraturan yang ada. Oleh kerana itu Pemerintah Desa Tegalrejo pada tahun 2018 akan merevisi RPJM Desa menjadi jangka waktu untuk perencanaan pembangunan tahun 2014-2020 atau enam tahun dalam satu periode pemerintahan serta menyesuaikan dengan RPJMD Kabupaten Gunungkidul. RPJMD Kabupaten Gunungkidul memiliki fokus pembangunan di sektor pariwisata mengingat Kabupaten Gungkidul merupakan salah satu kabupaten berlokasi di Provinsi DIY yang memiliki potensi sektor pariwisata yang besar. Mempersiapkan hal itu, Pemerintah Desa Tegalrejo akan mengembangkan potensi wisata yang dimilikinya. Desa Tegalrejo memiliki Curug Tegalrejo dan kampung pembuatan batik yang Bulan Agustus 2017 telah diresmikan oleh Sri Sultan Hamengkubuwono X.

Kemudian Dana Desa yang diperuntukkan dalam pembangunan infrastruktur berjumlah $\mathrm{Rp}$ 403.533.600 atau $29,7 \%$ dari total keseluruan Rp 818.533.600 Dana Desa yang diperuntukkan dalam sektor pembangunan secara keseluruhan di Desa Tegalrejo. Tabel keseuaian antara anggaran yang ada dalam dokumen RPJM Desa, RKP Desa, dan APB Desa Tegalrejo dapat dilihat pada tabel di bawah ini:

\section{Tabel 1}

Anggaran Program Pembangunan

Infrastruktur Dasar Desa yang

bersumber dari Dana Desa Tahun

2016

\begin{tabular}{lcccc}
\hline \multicolumn{1}{c}{ Uraian } & $\begin{array}{c}\text { RPJM } \\
\text { Desa } \\
\text { Tegalrejo } \\
(\text { Rp) }\end{array}$ & $\begin{array}{c}\text { RKP Desa } \\
\text { Tegalrejo } \\
(\text { Rp })\end{array}$ & $\begin{array}{c}\text { APB Desa } \\
\text { Tegalrejo } \\
(\text { Rp })\end{array}$ & Keterangan \\
\hline $\begin{array}{l}\text { Pembangunan } \\
\text { Jalan Desa }\end{array}$ & 20.000 .000 & 20.000 .000 & 20.000 .000 & Sesuai \\
\hline $\begin{array}{l}\text { Pembangunan } \\
\text { Jalan Pemukiman } \\
11 \text { Padukuhan }\end{array}$ & 110.000 .000 & 110.000 .000 & 110.000 .000 & Sesuai \\
$\begin{array}{l}\text { Pembangunan } \\
\text { Turap Talut } \\
\text { Bronjongan Jalan } \\
\text { Desa }\end{array}$ & 181.000 .000 & 181.000 .000 & 181.000 .000 & Sesuai \\
\hline $\begin{array}{l}\text { Pembangunan } \\
\text { Saluran Drainase } \\
\text { Gorong-gorong }\end{array}$ & 67.533 .600 & 67.533 .600 & 67.533 .600 & Sesuai \\
\hline & & & & \\
\hline
\end{tabular}


Vol.05, No.01, April 2019

Doi: $10.24198 /$ cosmogov.v2i2.xxxxx

\begin{tabular}{|c|c|c|c|c|}
\hline $\begin{array}{l}\text { Rehabilitasi } \\
\text { Pemeliharaan Cor } \\
\text { Rabat/Turap/Talut/ } \\
\text { Brojongan jalan } \\
\text { desa }\end{array}$ & 25.000 .000 & 25.000 .000 & 25.000 .000 & Sesuai \\
\hline Jumlah & 403.533.600 & 403.533.600 & 403.533.600 & \\
\hline Sumbe & $\begin{array}{l}\text { Diolah d } \\
\text { Desa, RI } \\
\text { Tegalrej } \\
2016 .\end{array}$ & $\begin{array}{l}\text { ri dokum } \\
\text { P Desa, a } \\
\text { Desa Te }\end{array}$ & $\begin{array}{l}\text { n RPJM } \\
\text { in APB Desa } \\
\text { alrejo tahun }\end{array}$ & \\
\hline
\end{tabular}

pengelolaan Dana Desa yang diperuntukkan dalam pembangunan infrastruktur.

BPD dan Masyarakat Desa Tegalrejo memiliki wewenang untuk mengiring perjalanan pengelolaan Dana Desa yang dilaksanakan oleh

Berdasarkan keterangan dalam tabel di atas, bahwa adanya kesesuaian antara keuangan yang dicatat dalam dokumen RPJM Desa, RKP Desa dan APB Desa Tegalrejo tahun 2016. Selain kesesuaian di atas, bahwa untuk mengukur akuntabilitas dalam pengelolaan Dana Desa harus adanya kesesuaian pelaksanaan pengelolaan Dana Desa untuk pembangunan infrastruktur dengan peraturan yang berlaku serta adanya kesesuaian evaluasi pengelolaan dana desa untuk pembangunan infrastruktur dengan peraturan yang berlaku. Pelaksanaan pembangunan infrastruktur di Desa Tegalrejo harus memiliki pengawasan. Peraturan Bupati Gunungkidul Nomor 49 Tahun 2015 tentang Pedoman Pengelolaan Keuangan Desa menyebutkan bahwa BPD adalah perwakilan dari masyarakat yang dipilih berdasarkan demokrasi keterwakilan wilayah di desa. BPD memiliki tugas sebagai pengawas pengelolaan keuangan desa yang pembiayaannya berada dalam APB Desa. Dalam pelaksanaannya BPD memiliki wewenang yang sangat mendasar dalam pengelolaan keuangan desa, khususnya Pemerintah Desa Tegalrejo mulai dari proses perencanaan hingga evaluasi. Seperti yang terjadi di lapangan bahwa dalam setiap kegiatan pelaksanaan khususnya pembangunan infrastruktur, masyarakat dan BPD selalu dilibatkan dalam pelaksanaanya. Kapasitas yang dimiliki BPD menjadikan sangat sentral untuk berpartisipasi dalam pelaksanaan pemerintahan. Hasil wawancara dengan Ketua BPD Tegalrejo, Jumadi menjelaskan bahwa Pemerintah Desa Tegalrejo dalam pelaksanaan yang khususnya berkaitan dengan pengelolaan Dana Desa selalu melibatkan BPD sebagai pengawas dan perwakilan dari masyarakat Desa tegalrejo untuk mengetahui dan mengawal keuangan desa. Keuangan desa yang nantinya diperuntukkan dalam pembangunan infrastruktrur harus disetujui dan disampaikan kepada pemerintah di atasnya dan kepada masyarakat Desa Tegalrejo (wawancara tanggal 23/10/2017 pukul 10.00 WIB).

Secara keseluruhan kesesuaian pengelolaan dana desa untuk pembangunan infrastruktur dengan peraturan yang berlaku masih kurang baik. Terlepas dari kesesuaian antara anggaran untuk pembangunan 
Vol.05, No.01, April 2019

Doi: 10.24198/cosmogov.v2i2.xxxxx

insfrastruktur yang tercatat dalam RPJM Desa, RKP Desa dan APB Desa Tegalrejo tahun 2016, adanya ketidaksesuaian antara RPJM Desa yang diatur dalam Perbup Gunungkidul No. 49 Tahun 2015. Perbup tersebut menjelaskan bahwa RPJM Desa harus untuk perencanaan pembangunan selama enam tahun atau satu periode pemerintahan kepala desa, sedangkan RPJM Desa yang ada di Desa Tegalrejo hanya untuk lima tahun (2014-2019).

\section{Kesesuaian Perencanaan dan Realisasi Pengelolaan Dana Desa serta Waktu Pelaksanaan Pembangunan Infrastruktur}

Pengelolaan Dana Desa harus memiliki kesesuaian antara perencanaan dan realisasi anggaran serta waktu perencanaan program. Hal tersebut bertujuan untuk memastikan pengelolaan Dana Desa dapat dirasakan manfaatnya oleh masyarakat. Selain itu, untuk menjamin tercapainya tujuan pembangunan desa sesuai dengan target yang telah di tetapkan. Pengelolaan Dana Desa untuk pembangunan infrastruktur di Desa Tegalrejo pada tahun 2016 yang pertama telah adanya kesesuaian antara perencanaan dan realisasi anggaran untuk pembangunan infrastruktur. Sementara dari segi waktu pelaksanaan pembangunan infrastruktur secara waktu realisasi penyelesaiannya sudah sesuai dengan rencana waktu pelaksanaan pembangunan infrastruktur yang telah di tentukan. Namun dalam dokumen pelaksanaan tersebut hanya sebatas waktu yang dibutuhkan untuk menyelesaikan program pembangunan infrastruktur, tidak ada rincian kapan waktu pelaksaannya seperti yang dijelaskan pada tabel 1.2 berikut ini:

Tabel 2

Kesesuaian antara Rencana

Waktu dan Realisasi Waktu

Pembangunan Infrastruktur

Desa Tegalrejo Tahun 2016

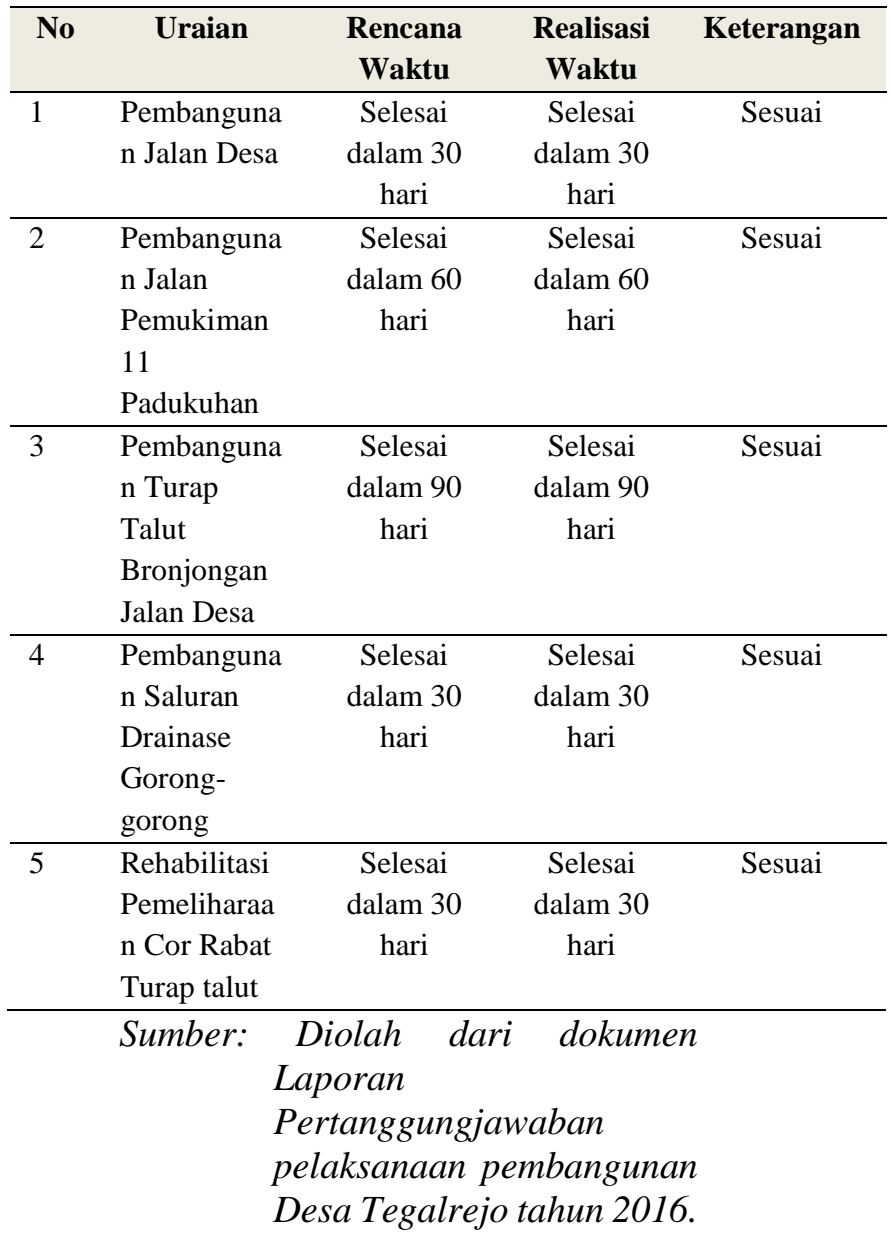

$\begin{array}{lcr}\text { Kesesuaian } & \text { antara rencana } \\ \text { waktu dan } & \text { realisasi } & \text { waktu } \\ \text { pembangunan infrastruktur } & \text { Desa }\end{array}$


Vol.05, No.01, April 2019

Doi: $10.24198 /$ cosmogov.v2i2.xxxxx

Tegalrejo pada tahun 2016 masih kurang baik. Karena dalam perencanaan dan pelaksanaan pembangunan infrastruktur di Desa Tegalrejo tidak dilampirkan kapan waktu pelaksanaan kegiatannya, hanya ada jangka rencana dan pelaksanaan kegiatannya saja,

3. Transparansi Pengelolaan Dana Desa dalam Program Pembangunan Infrastruktur oleh Pemerintah Desa

Transparansi

pengelolaan Dana Desa akan menjadikan masyarakat lebih percaya terhadap pemerintah desa karena masyarakat dapat mengetahui apa yang telah direncanakan dan di laksanakan oleh pemerintah Desa Tegalrejo khususnya untuk pembangunan infrastruktur. Selain itu, pengelolaan Dana Desa dapat dipertanggungjawabkan

penggunaannya kepada masyarakat. Sebagaimana yang disampaikan oleh Sugiman selaku Kepala Desa Tegalrejo menjelaskan bahwa Pertanggungjawaban penggunaan Dana Desa dalam pembangunan infrastruktur menurut sudah disesuaikan dengan Perbup Gunungkidul No. 49 Tahun 2015. Berikut ini merupakan alur pertanggungjawaban transparansi pengelolaan Dana di Desa Tegalrejo untuk pembangunan infrastruktur tahun 2016:

\section{Gambar 2}

Alur Pertanggungjawaban

Pengelolaan Dana Desa dalam

Pembangunan Infrastruktur di

Desa Tegalrejo Tahun 2016

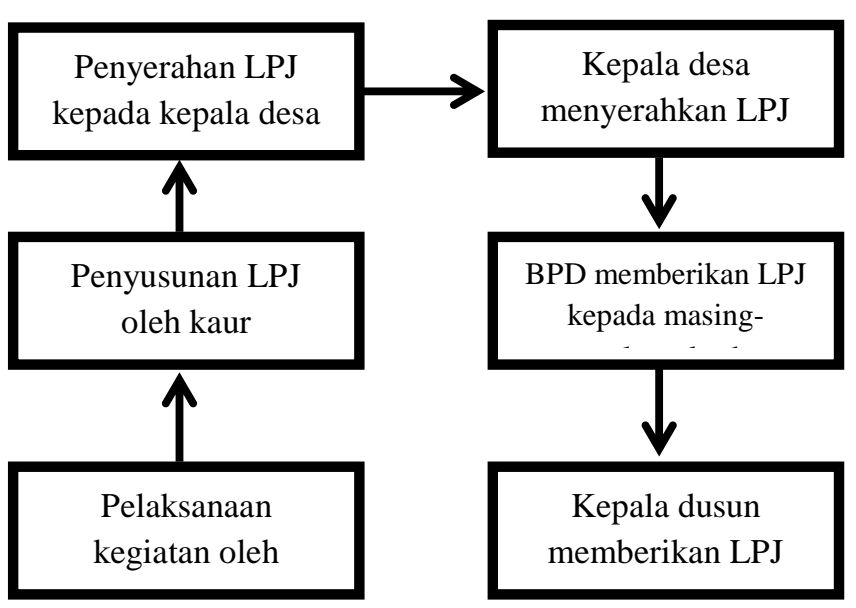

Sumber: Diolah dari data primer, 2017

Pertanggungjawaban

pengelolaan Dana Desa yang dilakukan Pemerintah Desa Tegalrejo dalam pembangunan infrastruktur tahun 2016 terdapat enam alur yaitu: Pertama, masyarakat dilibatkan langsung dalam pelaksanaan pembangunan infrastruktur. Langkah ini agar masyarakat merasa lebih puas dan bentuk pembangunan infrastruktur yang diharapkan oleh masyarakat akan sesuai dengan yang diharapkan; Kedua, kepala urusan bidang pembangunan Desa Tegalrejo membuat Laporan Pertanggungjawaban dalam bentuk dokumen dan lisan kepada Kepala Desa Tegalrejo; Ketiga, kepala urusan bidang pembangunan memberikan Laporan Pertanggungjawaban kepada kepala desa dalam setiap kegiatan 
Vol.05, No.01, April 2019

Doi: $10.24198 /$ cosmogov.v2i2.xxxxx

yang berkaitan dengan pembangunan disampaikan kepada kepala desa dalam rincian yang mendalam, kemudian untuk mengkaji ulang dan mengevaluasi pelaksanaan kegiatan pembangunan infrastruktur dalam bentuk rapat internal pemerintah desa sebelum disampaikan oleh masyarakat.

Keempat, kepala desa menerima laporan dari kepala urusan pembangunan, kemudian kepala desa memberikan

Laporan

Pertanggungjawaban kepada BPD Tegalrejo, kemudian mengadakan pertemuan dengan kepala dusun dan lima perwakilan tokoh masyarakat Desa Tegalrejo untuk memaparkan laporan kegiatan yang telah dilaksanakan Pemerintah DesaTegalrejo. Kelima, BPD memberikan laporan kepada kepala dusun untuk disampaikan kepada masyarakat. Kepala dusun memiliki kapasitas sebagai koordinator yang dapat memberikan laporan kepada masyarakat terkait bentuk penyampaian laporan pertanggungjawaban program kerja Pemerintah Desa Tegalrejo. Kemudian BPD memiliki peranan yang penting bersama masyarakat seperti yang tertera dalam Perbup No. 49 Tahun 2015 yang berbunyi, BPD melakukan pengawasan secara umum terhadap pengelolaan keuangan desa dalam rangka pelaksanaan peraturan desa tentang APB Desa. BPD Tegalrejo memiliki fungsi mengawasi transparansi pengelolaan keuangan
Desa Tegalrejo dalam rangka pelaksanaan peraturan desa tentang APB Desa.

Keenam, masyarakat menerima Laporan Pelaksanaan Pemerintahan Desa Tegalrejo untuk pembangunan infrastruktur tahun 2016 dalam sebuah pertemuan yang di adakan oleh masing-masing dusun. Selanjutnya setelah pertemuan tersebut masing-masing kepala dusun akan melakukan pertemuan dengan masing-masing Ketua RT dengan masyarakat yang berada di wilayah masing-masing pedukuhan untuk menyampaikan hasil laporan yang disampaikan kepala desa kepada masyarakat Desa Tegalrejo (koordinasi perdusun).

Transparansi pengelolaan keuangan Desa Tegalrejo tahun 2016 masih kurang baik. Sebagaimana yang dijelaskan oleh Purwanto selaku warga masyarakat Desa Tegalrejo bahwa Pemerintah Desa kurang aktif dalam menggunakan website untuk menginformasikan laporan kegiatan desa masih belum diunggah dalam website seperti yang terlihat pada gambar di bawah ini: 


\section{Gambar 3}

Website Desa Tegalrejo

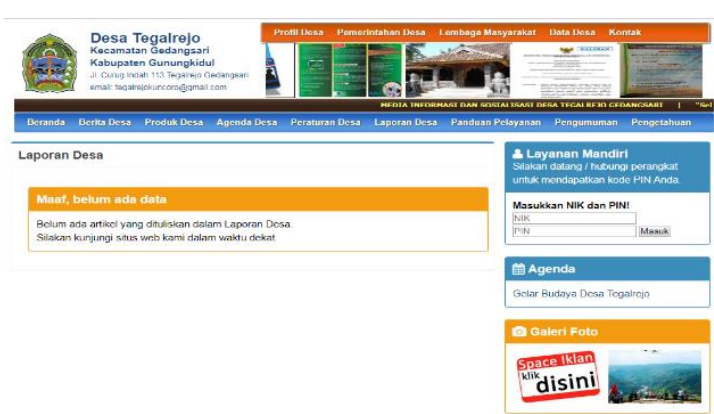

Sumber: Diolah dari website Desa Tegalrejo, 2017

Kemudian, contoh selanjutnya adalah penyampaian informasi yang berbentuk laporan perdusun terkait pembangunan jalan dusun, masyarakat baru diberi informasi jauh setelah pelaksanaan pembangunan jalan dusun terlaksana, dan hasilnya tidak sesuai dengan apa yang telah direncanakan terutama dalam bentuk anggaran. Contohnya adalah pembelian semen yang harga di toko per sak semen adalah Rp 40.000, sedangkan di laporan di lambungkan harganya menjadi $\mathrm{Rp}$ 45.000. biar bagaimanapun juga yang memilih bahan untuk bangunan adalah dari masyarakat, dan masyarakat juga mengetahui harganya. Kemudian di periode ini Pemerintah Desa Tegalrejo tidak begitu cepat dalam pembangunan khususnya pembangunan infrastrukturnya (wawancara tanggal 22 Oktober 2017 pukul 11.45 WIB).

Berdasarkan temuan tersebut dapat dianalisi bahwa akuntabilitas pengelolaan dana dawesa untuk pembangunan infrastruktur kurang baik disebabkan oleh berberapa faktor yaitu sebagai berikut:

Pertama, dari segi perencanaan yang melibatkan masyarakat, Pemerintah Desa Tegalrejo cenderung hanya melibatkan masyarakat yang selalu setuju dengan kebijakan yang ditentukan oleh pemerintah desa. Sedangkan masyarakat yang benar-benar memikirkan keberlangsungan pengelolaan Dana Desa agar tepat sasaran (kritis), malah tidak di libatkan dalam Musrenbang Desa Tegalrejo. Kedua, pelaksanaan pembangunan infrastruktur di Desa Tegalrejo pada tahun 2016 selalu melibatkan masyarakat baik keterlibatan bentuk fisik maupun finansial. Kemudian setiap pelaksanaan kegiatan dimasingmasing proyek pembangunan infrastruktur, diinformasikan melalui papan informasi yang disediakan tiap dusun dan tiap obyek pelaksanaan kegiatan pembangunan infrastruktur.

Ketiga, bentuk evaluasi yang melibatkan masyarakat dalam transparansi pengelolaan Dana Desa untuk pembangunan infrastruktur di Desa Tegalrejo diantaranya adalah: Keluhan masyarakat yang menyampaikan adanya selisih jumlah anggaran antara jumlah anggaran yang sesuai di pasar dengan realisasi. Kemudian dalam penyampaian bentuk Sistem Informasi Desa (SID) website desa yang masih kurang baik. 
Vol.05, No.01, April 2019

Doi: 10.24198/cosmogov.v2i2.xxxxx

Hal itu disebabkan karena SDM yang kurang memadai untuk menjalankan tugas ini dan harus adanya pendampingan terhadap pengelolaan website desa agar dapat menyampaikan bentuk laporan desa bukan hanya dalam program pembangunan infrastruktur saja, namun dalam keseluruhan program kerja kegiatan Pemerintah Desa Tegalrejo, sehingga dapat tercapainya pemerintahan yang transparansi dan akuntabel.

\section{Partisipasi Masyarakat dalam Program Pembangunan Infrastruktur Desa}

Partisipasi masyarakat sangatlah penting dalam pelaksanaan program yang dilakukan oleh pemerintah desa, salah satunya adalah keikutsertaan masyarakat dalam pembangunan infrastruktur. Karena bagaimanapun juga masyarakat adalah tujuan utama dalam pelaksanakan arah kebijakan oleh pemerintah desa yang memiliki tujuan meningkatkan kesejahteraan bagi masyarakat pedesaan. Partisipasi masyarakat dalam pembangunan infrastruktur desa dibagi menjadi tiga yaitu, partisipasi masyarakat dalam perencanaan, pelaksanaan, dan evaluasi program pembangunan infrastruktur desa.

Partisipasi masyarakat dalam perencanaan program pembangunan infrastruktur Desa Tegalrejo diawali dengan adanya rapat pembahasan tiap RT dengan waktu pelaksanakan satu kali dalam setiap program kegiatan pembangunan, di dalam rapat tersebut membahas tentang pelaksanaan program kegiatan pembangunan dan membahas tentang swadaya masyarakat yang diikutsertakan dalam pelaksanaan program pembangunan infrastruktur. Selanjutnya yaitu musyawarah dusun yang dilaksanakan juga dalam satu kali tiap program kegiatan, agenda di dalamnya adalah membahas tentang apa yang menjadi prioritas dalam pembangunan infrastruktur dan membahas tentang lokasi pelaksanaannya. Berikut ini merupakan bentukan partisipasi masyarakat Desa Tegalrejo dalam perencanaan pembangunan infrastruktur:

Tabel 3

Bentuk Partisipasi Masyarakat dalam Perencanaan Pembangunan Desa

\begin{tabular}{|c|c|c|c|}
\hline $\begin{array}{l}\mathbf{N} \\
\mathbf{o}\end{array}$ & $\begin{array}{c}\text { Nama } \\
\text { Kegiatan }\end{array}$ & $\begin{array}{c}\text { Waktu } \\
\text { Pelaksanaa } \\
\text { n }\end{array}$ & Keterangan \\
\hline 1 & Rapat RT & $\begin{array}{l}\text { Satu kali } \\
\text { program } \\
\text { kegiatan }\end{array}$ & $\begin{array}{l}\text { membahas } \\
\text { pelaksanaan } \\
\text { program } \\
\text { kegiatan dan } \\
\text { swadaya } \\
\text { masyarakat }\end{array}$ \\
\hline 2 & $\begin{array}{l}\text { Musyawara } \\
\text { h Dusun }\end{array}$ & $\begin{array}{l}\text { Satu kali tiap } \\
\text { program } \\
\text { kegiatan }\end{array}$ & $\begin{array}{l}\text { Membahas } \\
\text { pelaksanaan } \\
\text { pembanguna } \\
\text { n di tiap titik } \\
\text { yang menjadi } \\
\text { prioritas }\end{array}$ \\
\hline 3 & $\begin{array}{l}\text { Rapat } \\
\text { Koordinasi } \\
\text { Perwakilan } \\
\text { Stakeholder } \\
\text { s Desa } \\
\text { Tegalrejo }\end{array}$ & $\begin{array}{l}\text { Setiap hari } \\
\text { senin }\end{array}$ & $\begin{array}{l}\text { Monev } \\
\text { kegiatan } \\
\text { pelaksanaan } \\
\text { pembanguna } \\
\mathrm{n} \\
\text { infrastruktur }\end{array}$ \\
\hline 4 & Musrenbang & $\begin{array}{l}\text { Satu kali di } \\
\text { akhir tahun }\end{array}$ & $\begin{array}{l}\text { Masyarakat } \\
\text { hadir dan } \\
\text { mengevaluasi }\end{array}$ \\
\hline
\end{tabular}


Vol.05, No.01, April 2019

Doi: 10.24198/cosmogov.v2i2.xxxxx

\begin{tabular}{ll}
\hline & program \\
pelaksanaan \\
pembanguna \\
$\mathrm{n}$ \\
infrastruktur \\
selama satu \\
tahun \\
\hline
\end{tabular}

Sumber: Diolah dari data primer, 2017.

Partisipasi masyarakat Desa Tegalrejo dalam pengelolaan dana desa untuk pembangunan infrastruktur dapat disimpulkan bahwa partisipasi tersebut sesuai dengan teori dari Soetrisno (1995), bahwa ada dua model partisipasi masyarakat, yaitu partisipasi murni dan semu. Pertama, partisipasi murni yaitu keterlibatan masyarakat dalam menganalisis bentuk laporan pelaksanaan kegiatan, dan keikutsertaan Masyarakat Desa Tegalrejo dalam pelaksanaan kegiatan hingga melakukan swadaya masyarakat untuk pelaksanaan pembangunan infrastruktur seperti temuan analisis di atas. Kedua, partisipasi semu dikaitkan dengan rapat koordinasi yang dilaksanakan oleh Pemerintah Desa Tegalrejo tidak melibatkan masyarakat yang aktif dalam mengkritisi kinerja pemerintah, melainkan yang dilibatkan hanya masyarakat yang berpihak pada pemerintah desa untuk melaksanakan program pembangunan infrastruktur.

\section{KESIMPULAN}

Berdasarkan hasil penelitian dan analisis di atas, maka dapat disimpulkan bahwa akuntabilitas pengelolaan dana desa untuk pembangunan infrastruktur di Desa Tegalrejo kurang baik. Hal ini dikarenakan berberapa faktor yaitu sebagai berikut: Belum ada rincian waktu terkait waktu pelaksanaan program pembangunan infrastruktur; Kurang transparan dalam menyampaikan laporan pengelolaan anggaran dalam pembangunan infrastruktur; Belum semuanya masyarakat berpartisipasi aktif dalam pelaksanaan pembangunan infrastruktur; Belum maksimal dalam pemanfaatan Sistem Internet Desa (SID) sebagai sarana untuk menginformasikan laporan pengelolaan Dana Desa untuk pembangunan infrastruktur; dan Perangkat desa yang kurang berkoordinasi dengan masyarakat terkait pelaksanaan pembangunan infrastruktur.

\section{DAFTAR PUSTAKA}

Astuty, E., \& Fanida, E. H. (2013). Akuntabilitas Pemerintah Desa dalam Pengelolaan Anggaran Pendapatan dan Belanja Desa (APBDES) (Studi pada Alokasi Dana Desa Tahun Anggaran 2011 di Desa Sareng Kecamatan Geger Kabupaten Madiun). Surabaya: Universitas Negeri Surabaya. Husein, S, K. H. (2017). Evaluasi Pemanfaatan Dana Desa untuk Pembangunan 
Vol.05, No.01, April 2019

Doi: $10.24198 /$ cosmogov.v2i2.xxxxx

Infrastruktur. Yogyakarta: Universitas Muhammadiyah Yogyakarta.

Henry, Stepanus. (2013). Partisipasi

Masyarakat

Dalam

Pembangunan di Kelurahan

Sungai Keledang Kecamatan

Samarinda Seberang Kota

Samarinda. Jurnal Ilmu

Pemerintahan, Vol.1, No.2,

612-625.

Fajar, T. (2016). Sistem Akuntabilitas

Keunangan Desa (Studi

Kasus: Desa Temuwuh dan

Terong, Kecamatan Dlinglo,

Kabupaten

Bantul).

Yogyakarta: Universitas

Muhammadiyah Yogyakarta.

Riyanto, T. (2015). Akuntabilitas

Finansial Dalam Pengelolaan

Alokasi Dana Desa (ADD) Di

Kantor Desa Perangat

Selatan Kecamatan

Marangkayu Kabupaten Kutai

Kartanegara. Samarinda:

Universitas Mulawarman.

Sina, A, I. (2017). Implementasi

Transparansi dan

Akuntabilitas sebagai Upaya

Pencegahan Korupsi (Studi

pada DPC PKB di Ngawi).

Surakarta: IAIN Surakarta.

Moleong, J. 2009. Metodologi

Penelitian Kualitatif.

Bandung: Remaja

Rosdakarya.

Peraturan Menteri Dalam

Negeri Nomor 113 Tahun

2014 tentang Pengelolaan

Keuangan Desa.
Nyoman. (1991). Pembangunan Desa

Berwawasan Lingkungan.

Jakarta: Bumi Aksara. 1991.

Hal 48.

Safi'I. (2009). Manajemen

Pembangunan Daerah "Teori

dan Aplikasi”. Malang:

Averroes Press.

Soetrisno, L. (1995). Мепији

Partisipasi Maasyarakat.

Yogyakarta: Kanisius.

Undang-undang Nomor 6 Tahun

2014 tentang Desa.

Peraturan Bupati

Gununungkidul Nomor 49

Tahun 2015 tentang Pedoman

Pengelolaan Keuangan Desa.

Anggaran Pendapatan dan Belanja

Desa Tegalrejo Tahun 2016.

Laporan Pertanggungjawaban

Pelaksanaan Pembangunan

Desa Tegalrejo tahun 2016.

Rencana Pembangunan Jangka

Menengah Desa Tegalrejo

Tahun 2014-2019.

Rencana Kerja Pemerintah Desa

Tegalrejo Tahun 2016. 